\title{
STUDIES ON REANIMATION WITH PLASMA EXPANDERS
}

\author{
BY \\ C. T. NICOLAU, CECIL POPPA, M. IALOMITEANU, R. PÎRVU, AND \\ M. IONESCU \\ From the Institute of Haematology, Bucharest, Rumania
}

(RECEIVED FOR PUBLICATION APRIL 16, 1960)

\begin{abstract}
In dogs very severe haemorrhage, which leads to a state barely distinguishable from death, can be cured by one intra-arterial injection of dextran equal in volume to three-quarters or more of the estimated blood loss, provided that the dextran injection contains adrenaline and lobeline. Recovery after this treatment is only temporary, and a blood transfusion of about $25 \%$ of th e subject's lost volume of blood is needed for complete recovery.

It may be possible to apply these results to man, in which case, the reanimation method of Negovsky could be simplified and therefore be easy to use in any circumstances.
\end{abstract}

The progress of surgery during the last 20 years has depended largely on the improvements in the techniques of anaesthesia, the discovery and application of antibiotics, and the widespread use of blood transfusion. During the last 10 years the use of blood transfusion has attained first importance in treating patients suffering from surgical shock and particularly those who have bled freely. In Britain the infusion of blood, plasma or plasma substitutes, usually intravenously, sometimes by the intra-arterial route (Devitt and Widgerow, 1951 ; Bingham, 1952 ; Brown, 1953 ; Horton, Inkster, Mackenzie, and Pask, 1953 ; Maloney, Smythe, Gilmore, and Handford, 1953), has been the treatment of choice in all patients who have lost large volumes of blood, but Negovsky in the Soviet Union has developed a more complex method applicable even to patients on the brink of death. $\mathrm{He}$ injects intra-arterially blood to which adrenaline has been added and at the same time introduces an intratracheal tube through which oxygen is taken to the lungs (Negovsky, 1945 and 1954).

We have previously shown (Nicolau and Poppa, 1958) that this method will prevent clinical death even when a macromolecular substance, such as dextran, is used in place of blood. Recovery from shock achieved in this way is temporary, lasting only six to eight hours, and for permanent recovery blood must be administered subsequently.

For the success of the Negovsky method intratracheal insufflation of oxygen is essential, but this is inconvenient. In this paper we report our attempts to relieve post-haemorrhagic shock by perfusion of dextran and adrenaline with the addition of lobeline. The hypothesis was that the direct action of lobeline on the respiratory centre should make oxygen therapy unnecessary.

\section{Experimental}

Studies were performed on 26 dogs (weight 14-16 kg.), of which eight were controls which received saline in place of dextran, adrenaline, and lobeline.

Procedure.-Blood volume was determined with T 1824 (Porat, 1951) and narcosis with sodium evipan (30 mg./ $/ \mathrm{kg}$. body weight). Heparin was given in a dose of $4 \mathrm{mg}$. (250 I.U.)/kg. body weight. Blood was then removed from the carotid artery at the rate of $150 \mathrm{ml}$. per minute until 60 to $85 \%$ of the total blood volume had been removed. Dextran was perfused into the carotid artery (centripetal) at a rate of 150 $\mathrm{ml}$. per minute and a pressure of 180 to $200 \mathrm{~mm}$. of mercury, and $1 \mathrm{mg}$. adrenaline and $3 \mathrm{mg}$. lobeline injected with the blood substitute.

Blood pressure records were obtained with a mercury manometer connected with the femoral artery, and the respiratory movements from a pneumograph used with a Marey capsule. Records were made on smoked paper using Jaquet's electrokymograph with 6-second markers.

The experimental animals, after bleeding, were divided into two batches.

Group 1.-Nine animals received dextran equal in volume to the blood removed, and thereafter a blood transfusion equal to one-quarter of the blood removed ; in three animals at four hours after dextran, in three at six and three at eight hours. 


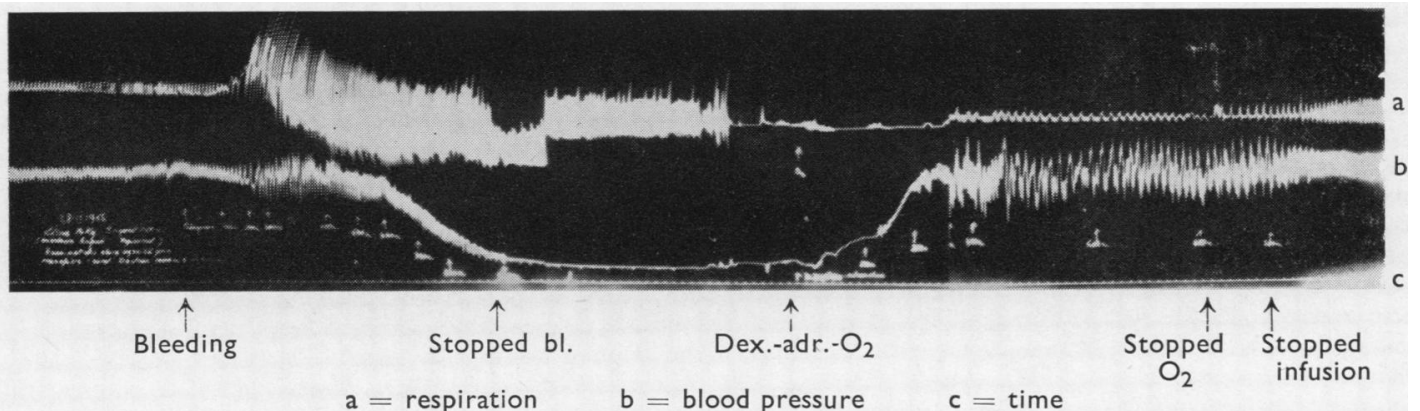

FIG. 1.-Recording from a dog reanimated from near death with dextran, adrenaline, and oxygen.

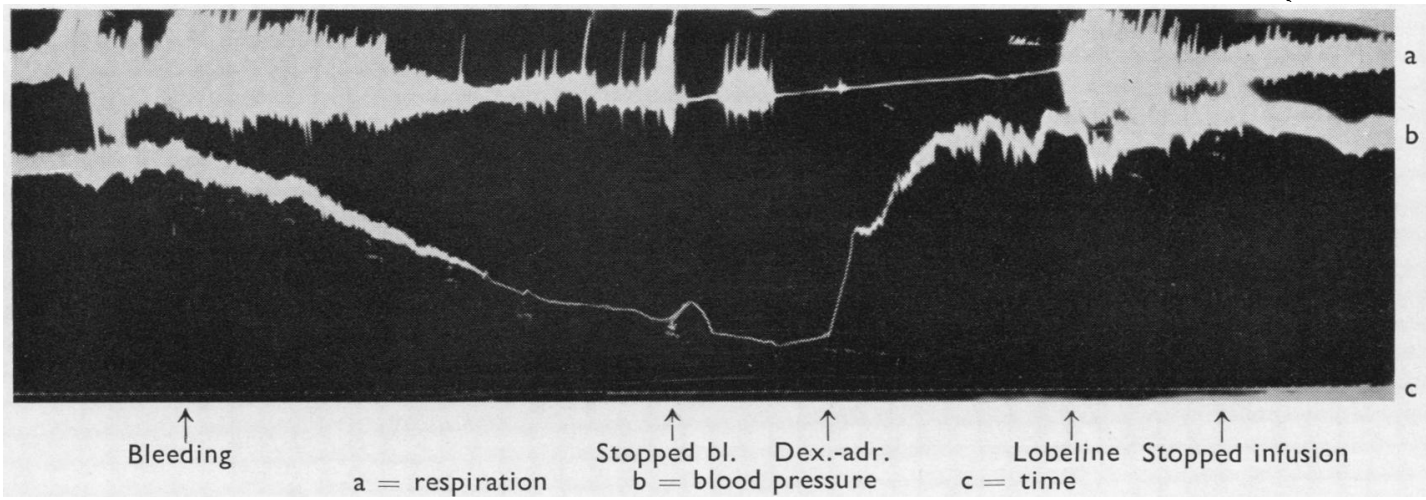

Fig. 2.-Recording from a dog reanimated from near death with dextran, adrenaline, and lobeline.

Group 2.-Nine animals also received dextran equal to $75 \%$ of the blood removed and thereafter a blood transfusion of $25 \%$ of the blood removed; in three animals at three hours, in three at five hours, and in three at seven hours after bleeding.

The controls received saline in place of dextran with adrenaline and lobeline, and thereafter a $25 \%$ blood transfusion was given at four and six hours.

\section{Results}

All the animals in the first two batches recovered completely. Of the control animals, six died within two hours and two recovered.

\section{Discussion}

One of the important points of the Negovsky method of resuscitation is the use of intratracheal insufflation. We have found that resuscitation depends on the simultaneous recovery of respiratory function (which seems to be achieved by intratracheal insufflation) and the vasomotor automatic reflex, which depends on stimulation of the pressure receptors in the arterial tree. Restoration of blood volume and even of circulation does not necessarily save the animal's life. Spontaneous respiratory activity must be established, and, with the original Negovsky method, this could be accomplished only by the intratracheal route. We doubted whether supply of large quantities of oxygen is really important, because exsanguinated animals have a very low metabolic rate, and we have previously demonstrated (Nicolau and Poppa, 1958) that the small volume of blood remaining in the vessels, the liver, and the spleen is enough to carry oxygen sufficient to keep the tissues alive. We therefore considered that the effect of oxygen treatment was to stimulate by a reflex route the respiratory centre in the bulb, which could be effected directly by some other drug, for example lobeline, which has been used for this purpose in newborn children for many years. This hypothesis was confirmed by the experiments reported here.

\section{Conclusion}

We consider that this may have great importance in medical practice, in small hospitals, maternity homes, or in emergencies where it is difficult to establish recovery from severe haemorrhagic shock, because the simultaneous performance of intra-arterial transfusion and of tracheal intuba- 
tion is rarely possible. Since we have shown that tracheal intubation is unnecessary it should now be possible to treat post-haemorrhagic shock by the intra-arterial administration of plasma expanders (in this instance dextran) combined with adrenaline and lobeline, provided that a blood transfusion of about one-quarter of the blood loss is given within six to eight hours of the initiation of treatment. The blood provides the vehicle for the oxygen which cannot be carried by macromolecular plasma expanders.

\section{REFERENCES}

Bingham, D. L. C. (1952). Lancet, 2, 157.

Brown, A. S. (1953). Ibid., 2, 745.

Devitt, D. C., and Widgerow, C. (1951). Brit. med. J., 2, 278.

Horton, J. A. G., Inkster, J. S., Mackenzie, A., and Pask, E. A. (1953). Anésth. et Analg., 9, 189.

Maloney, J. V. Jr., Smythe, C. McC., Gilmore, J. P., and Handford, S. W. (1953). Surg. Gynec. Obstet., 97, 529.

Negovsky, V. (1945). J. Amer. med. Ass., 129, 1226.

- (1954). Patofiziologhia $i$ terapia agonii $i$ klinicescoi smerti (The physiopathology and therapy of agony and clinical death.) Medgiz, Moscow.

Nicolau, C. T., and Poppa, C. G. (1958). Stud. Cercet. He mat., 4, 7. Porat, B. von (1951). Acta med. scand., 140, Suppl. 256.

\section{Association of Clinical Pathologists Broadsheets}

The following broadsheets (new series) are published by the Association of Clinical Pathologists. They may be obtained from Dr. F. Hampson, Department of Pathology, Royal Berkshire Hospital, Reading, price 1s. each.

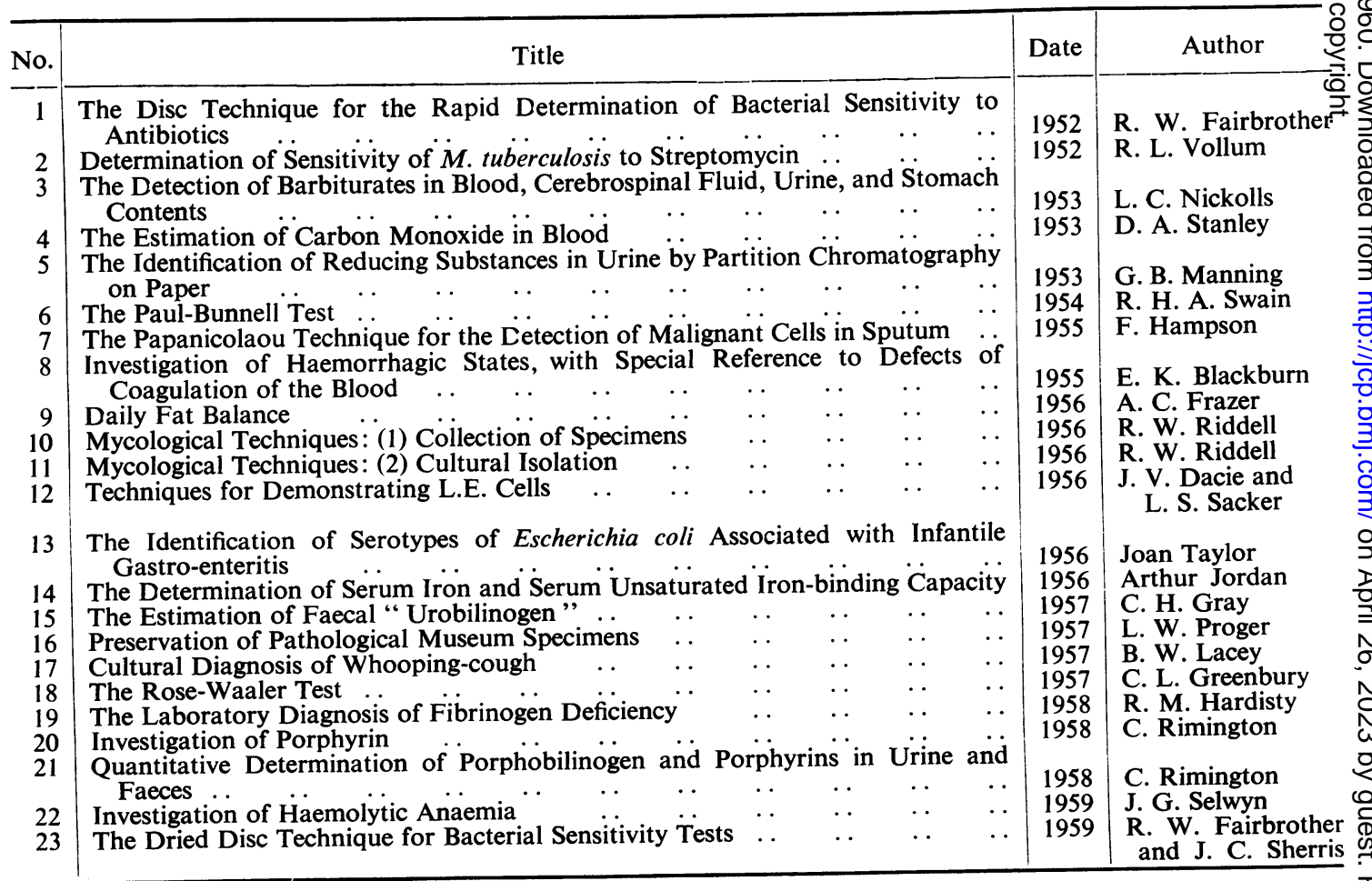

